\title{
Нови хирургични методи за лечение на тонзиларните проблеми
}

\author{
Хр. Златанов, В. Цветков, Г. Кукушев \\ УНГ-клиника при ВМА - София
}

\begin{abstract}
During a period of two years and tree months in the ENT department at the MMA (Military Medical Academy) Sofia 200 tonsillectomies were performed. $45 \%$ of the patients were operated using the conventional methods and the rest $55 \%$ were operated using Ultracision.

Our goal was to observe the effectiveness of this new method which is wide spread in the western countries.

We have observed the following criteria:

1. Early postoperative bleeding;

2. Late postoperative bleeding;

3. Pain requiring continuous analgetic intake.
\end{abstract}

\section{Резюме}

За период от две години и три месеца в УНГ-клиниката на BMA София бяха извършени 200 тонзилектомии на болни в различна възраст. От тях 45\% бяха оперирани конвенционално, а при останалите 55\% бе използван ултразвуков хармоничен скалпел Ultracision. За да проследим ефективността на този нов и широко застъпен в западните УНГ-клиники хирургичен метод, ние отчетохме следните показатели:

1. Ранно постоперативно кървене;

2. Късно постоперативно кървене;

3. Болка, налагаща непрекъснат прием на аналгетици.

Резултатите показаха чувствителна разлика в полза на ултразвуковата методика.

Ключови думи: тонзилектомия, ултразвуков скалпел, следоперативно кървене

\section{Въведение}

Има исторически данни за хирургичното лечение на сливиците от преди 2000 години. Основните оперативни техники са въведени в края на 19-ти и началото на 20-ти век.

До откриването на пеницилина индикациите за оперативна интервенция са обхващали повече критерии. По данни на американското дружество по УНГ-заболявания в периода 1943 г. и 1983 г. са се извършвали между 1 и 2 милиона тонзилектомии годишно. Днес бройката в САЩ е средно 250000 - 350000 годишно, като това остава втората по честота операция в областта на главата и шията.

Според най-новите гайдлайни тонзилектомия е показана при следните случаи:

Дефинитивни индикации:

- Чести епизоди на остри или хронични тонзилити;

- Перитонзиларен абсцес;

- Тонзиларна хипертрофия, която затруднява дишането или гълтането;

- Sleep apnea;

- Биопсия, нужна да докаже възможен малигнен процес;

- Тонзилити, водещи до фебрилни конвулсии;

- Дифтерийно носителство.

Релативни индикации:

- Големи тонзили или тонзиларни дебриди (понякога водещи до foetor ex ore); 
- Системно заболяване вторично от бета-хемолитичено стрептококова инфекция (ревматизъм, нефрит);

- Чести възпаления на горните дихателни пътища.

\section{Материали и методи}

Иновациите и разработките в областта на хирургичното лечение на сливиците доведоха до подобрение на ефикасността, безопасността, цената на процедурата и болничния престой. Една от тези иновации е ултразвуковият хармоничен скалпел Ultracision, който бе представен през 1993 г. от фирмата „Еthicon ${ }^{\circledR \lll}$ и бързо се наложи при оперативното лечение на тонзилите.

Преди използването им от УНГ-специалистите хармоничният скалпел Ultracision бе намерил широко приложение в лапароскопската и гинекологичната хирургия.

Предимството на тази техника е използването на ултразвук, чиято енергия позволява едновременно рязане и коагулация, точно и прецизно. Острието вибрира с 55,000 херца, което минимизира термалното увреждане на тъканите в съседство.

Причините за нарастващата популярност на хармоничния скалпел сред УНГ-специалистите са:

1. По-краткото оперативно време;

2. Операцията протича практически безкрьвно и атравматично за пациента;
3. Намаляване на постоперативната болка и общото неразположение;

4. По-ранен прием на течности и медикаменти.

За да докажем ефикасността на този нов метод, ние проведохме следното клинично проучване при 200 болни. При $45 \%$ от тях беше използвана конвенционална техника при тонзилектомията. При 55\% от тях бе използван ултразвуковият хармоничен скалпел.

Целта бе да определим разликите в интра- и постоперативното кървене, както и постоперативната болка, налагаща прием на аналгетици.

\section{Резултати и обсьждане}

Операцията протича на практика безкръвно. Оперативното поле е чисто и осигурява комфорта на хирурга, като спестява излишна кръвозагуба на пациента.

При оперираните с Ultracision ранното следоперативно кървене бе сведено до минимум. Близо 4-5 пъти бе намален този показател. Причина за това са параметрите на хармоничния ултразвуков скалпел, при който наред с отпрепарирането на тонзиларната тькан се прави и хемостаза на подлежащите малки съдове. Това облекчава ранния следоперативен период и обезсмисля прилагането на венозни кръвоспиращи медикаменти. На фигура 1 са представени процентите на пациентите с ранно постоперативно крьвотечение.

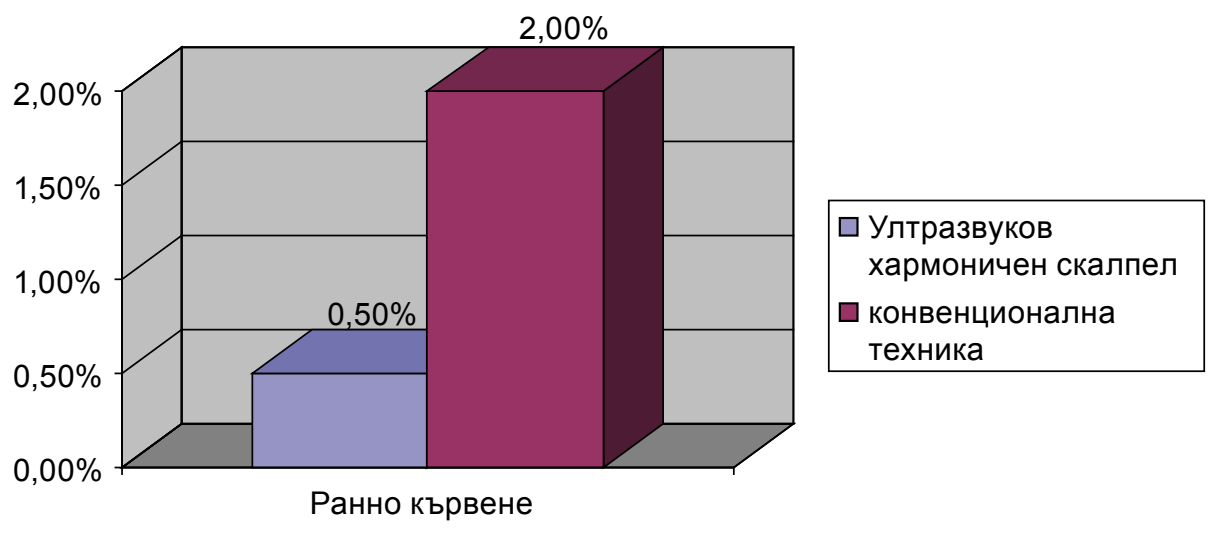

Пациентите, оплакващи се от кървене след оперативната интервенция (в първите 24 часа), са близо 10 пьти по-малко.

За УНГ-специалистите, използващи ултразвуковия хармоничен скалпел, е важно да отбележим, че постоперативните налепи отпадат средно с 2-3 дни по-късно от конвенционалната техника. 


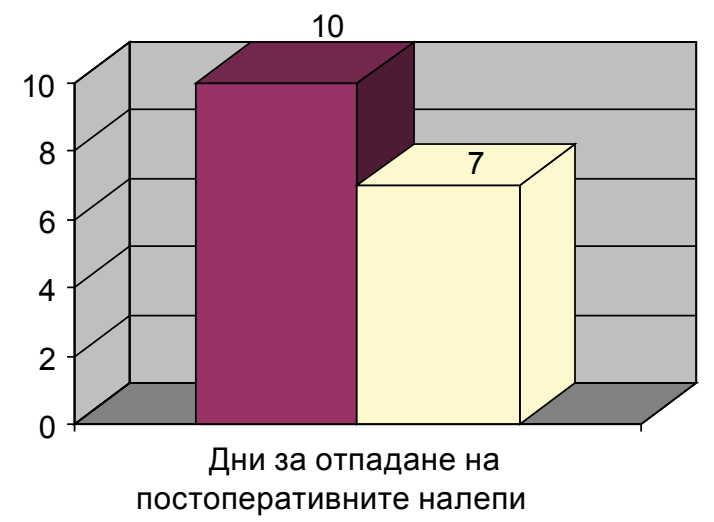

$\square$ ултразвуков

хармоничен скалпел

$\square$ конвенционална техника

\begin{tabular}{|c|c|}
\hline $\begin{array}{c}\text { Дни за отпадане на постоперативния налеп при } \\
\text { конвенционалната методика }\end{array}$ & $\begin{array}{c}\text { Дни за отпадане на постоперативния налеп при } \\
\text { Ultracision }\end{array}$ \\
\hline $7-8$ ден & 10 ден \\
\hline
\end{tabular}

По отношение на следоперативната болка, налагаща аналгетици, резултатите на болните, оперирани с Ultracision, също показват предимствата на тази нова оперативна техника. Това дава възможност за по-ранния прием на течности от пациентите.
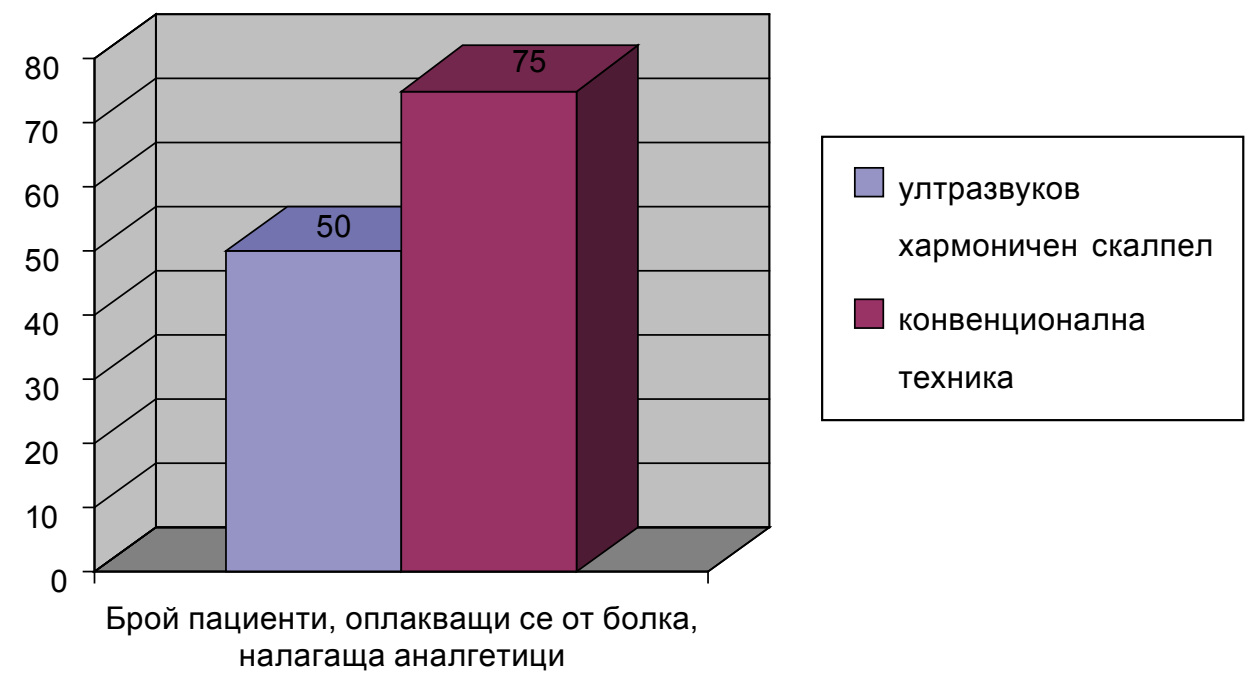

\begin{tabular}{|c|c|}
\hline $\begin{array}{c}\text { Процент пациенти, оплакващи се от болки, } \\
\text { оперирани с конвенционалната методика }\end{array}$ & $\begin{array}{c}\text { Процент пациенти, оплакващи се от болки, } \\
\text { оперирани c Ultracision }\end{array}$ \\
\hline $25 \%$ & $12,5 \%$ \\
\hline
\end{tabular}

При наблюдаваната група пациенти не бяха намерени съществени различия по отношение на късните хеморагии между оперираните с Ultracision и конвенционалната техника. Това най-вероятно се дължи на патофизиологичния им механизъм, а именно отпадане на постоперативния налеп и ерозия на подлежащ съд.

\section{Заключение}

Резултатите, както и субективните усещания на пациентите показват безспорните предимства на този метод. Нашата препорька към колегите УНГспециалисти е да прилагат рутинно този метод не само поради по-добрия оперативен комфорт и контрол, но и поради по-лекия постоперативен период за пациента. 
Литература:

1. Graham, John M.; Glenis K. Scadding, Peter D. Bull (2008). Pediatric ENT

2. Kramer SP, Pasha R. (2005). Otolaryngology: Head and Neck Surgery-A Clinical \& Reference Guide, Second Edition. Plural Publishing

3. Windfuhr JP, Chen YS, Remmert S. (2005). "Hemorrhage following tonsillectomy and adenoidectomy in 15,218 patients“. OtolaryngologyHead \& Neck Surgery
4. Stuck, B. A. et al.: „Die Tonsillektomie im Kindesalter.“ Dtsch Arztebl 2008

5. Hornibrook J (2009). "Response to: The role of tonsillectomy in reducing recurrent pharyngitis: A systematic review, from Jeremy Hornibrook

6. Brauer J, Kaschke O (2004): Nachblutung - ein reelles Risiko? HNONachrichten 